\title{
Untreated primary hypothyroidism with simultaneous rhabdomyolysis, pericardial effusion, and sudden sensorineural hearing loss: a case report
}

Chung Gyo Seo ${ }^{1}$, Kyoung Jin Kim¹, Euyhyun Park², Nam Hoon Kim', Joo Hyung Kim', Hee Young Kim, Sin Gon Kim ${ }^{1}$ and Kyeong Jin Kim ${ }^{1 *}$

\begin{abstract}
Background: Hypothyroidism, one of the prevalent endocrine disorders worldwide, has a broad spectrum of clinical manifestations, from an asymptomatic condition to myxedema coma. Although the majority of patients with hypothyroidism have minor clinical symptoms, which are recovered with levothyroxine treatment, some patients occasionally do experience fatal complications. Here we report, for the first time, the case of a patient who had hypothyroidism with simultaneous occurrence of rhabdomyolysis with acute kidney injury, moderate pericardial effusion, and sudden sensorineural hearing loss.

Case presentation: A 57-year-old man with a previous history of dyslipidemia and untreated hypothyroidism was admitted to the hospital due to shortness of breath, lethargy, lower extremity discomfort, and unilateral hearing loss. Laboratory results revealed rhabdomyolysis with acute kidney injury and severe hypothyroidism. We detected cardiomegaly without lung parenchymal infiltration on chest radiography and moderate pericardial effusion on transthoracic echocardiography. We performed pure tone audiometry and identified profound unilateral sensorineural hearing loss. Aggressive fluid resuscitation, levothyroxine treatment, and systemic and intratympanic steroid therapy alleviated the patient's severe hypothyroidism, rhabdomyolysis, and pericardial effusion; however, sensorineural hearing loss was not fully recovered.

Conclusions: Early recognition of life-threatening complications is important in patients with severe hypothyroidism to prevent adverse outcomes. This case suggests that hypothyroidism should be considered in patients who have rhabdomyolysis with acute kidney disease and pericardial effusion. Moreover, sudden sensorineural hearing loss should be kept in mind as a rare complication of hypothyroidism.
\end{abstract}

Keywords: Hypothyroidism, Rhabdomyolysis, Pericardial effusion, Hearing loss

\section{Background}

Hypothyroidism, characterized by elevated level of serum thyroid stimulating hormone (TSH) with lower or normal free thyroxine (fT4), is predominant worldwide, particularly in iodine-deficient regions [1-3]. Previous studies have reported that the general prevalence of hypothyroidism is 5$10 \%$ in women and $1-3 \%$ in men [4-6]. Clinical

\footnotetext{
* Correspondence: papaya0707@gmail.com

'Division of Endocrinology and Metabolism, Department of Internal Medicine, Korea University Anam Hospital, Korea University College of Medicine, 73 Inchon-ro, Seongbuk-gu, Seoul 02841, Republic of Korea Full list of author information is available at the end of the article
}

manifestations of hypothyroidism vary widely from asymptomatic or subclinical conditions to overt state of myxedema coma or multiorgan failure, depending on the age at diagnosis, the duration and severity of thyroid hormone deficiency. The most common symptoms of hypothyroidism are fatigue, cold sensitivity, constipation, dry skin, and weight gain. Carpal tunnel syndrome, voice change, and myopathy are less common signs and rhabdomyolysis, pericardial effusion, and sudden hearing loss are rare complications of hypothyroidism [1, 7]. Although previous studies have reported a few cases of these rare complications, such

(c) The Author(s). 2019 Open Access This article is distributed under the terms of the Creative Commons Attribution 4.0 International License (http://creativecommons.org/licenses/by/4.0/) which permits unrestricted use, distribution, and reproduction in any medium, provided you give appropriate credit to the original author(s) and the source, provide a link to the Creative Commons license, and indicate if changes were made. The Creative Commons Public Domain Dedication waiver (http://creativecommons.org/publicdomain/zero/1.0/) applies to the data made available in this article, unless otherwise stated. 
as rhabdomyolysis or pericardial effusion due to overt hypothyroidism [8-10], there are few reports of simultaneous occurrence of rare complications caused by primary hypothyroidism. Of particular note is that early recognition of combined complications induced by hypothyroidism is essential to treat patients who can recover with simple levothyroxine treatment.

In this regard, we describe an unusual case of severe hypothyroidism accompanied by rare complications of rhabdomyolysis with acute renal injury, pericardial effusion, and sudden sensorineural hearing loss at the same time.

\section{Case presentation}

A 57-year-old man presented to the emergency room with a several-day history of shortness of breath, nausea, dizziness, bilateral limb discomfort, and unilateral hearing loss. He also complained of cold intolerance and sluggish speech and movement that started a few weeks earlier, as well as 2 -kg weight gain over the past year. He started rosuvastatin (5 mg, once daily) a year ago, with no dose adjustment; the patient was diagnosed with hypothyroidism at the same time. He was recommended levothyroxine treatment but did not initiate treatment because he had no related symptoms or discomfort in his daily life.

General physical examination revealed dry skin, neck vein distension, nontender diffuse goiter around the neck, and myxedema with puffy face, bilateral periorbital and lower extremities edema. His pulse rate was 52 beats/minute, blood pressure was $114 / 82 \mathrm{mmHg}$, respiratory rate was 20 breaths/minute, and his body temperature was $37.1{ }^{\circ} \mathrm{C}$. Muffled heart sounds without fine crackle were also detected.

The initial results of laboratory tests (Table 1 ) were as follows: BUN 19.0 (7-23) $\mathrm{mg} / \mathrm{dL}$, creatinine $1.5(0.7-1.4)$ $\mathrm{mg} / \mathrm{dL}$, creatine kinase 9300 (43-198) IU/L, lactate dehydrogenase 1876 (238-422) IU/L, myoglobulin 636 (2872) $\mathrm{ng} / \mathrm{mL}$, alanine aminotransferase 357 (3-45) IU/L, aspartate aminotransferase 278 (3-45) IU/L, creatine kinase muscle-brain fraction (CK-MB) $52.07(0-4.87) \mathrm{U} / \mathrm{L}$, troponin I $0.057(0-0.014) \mathrm{ng} / \mathrm{mL}$, total cholesterol $222(130$ 240) $\mathrm{mg} / \mathrm{dL}$, low density lipoprotein cholesterol (LDL-c) $136(50-160) \mathrm{mg} / \mathrm{dL}$, high density lipoprotein cholesterol (HDL-c) 74 (40-85) mg/dL, and triglycerides 127 (35200) $\mathrm{mg} / \mathrm{dL}$. The results of thyroid function tests showed $\mathrm{TSH}>100(0.17-4.05) \quad \mu \mathrm{IU} / \mathrm{mL}$, fT4 $0.32(0.89-1.79)$ $\mu \mathrm{IU} / \mathrm{mL}$, and triiodothyronine (T3) $55.6(78-182) \mathrm{ng} / \mathrm{dL}$. On chest radiography, heart shadow was not blunted without pulmonary infiltration, and cardiomegaly was seen (cardiothoracic ratio, 66\%; Fig. 1a). An electrocardiogram showed bradycardia with normal sinus rhythm and low QRS voltage, and transthoracic echocardiography revealed a moderate amount of pericardial effusion (posterior 15

Table 1 Patient's laboratory values

\begin{tabular}{|c|c|c|c|c|c|c|}
\hline Variables & Reference range & Admission & Day 3 & Day 7 & Day 10 & Day 20 (Outpatient clinic) \\
\hline Hemoglobin, (g/dL) & $13.1-17.2$ & 12.0 & 12.9 & & 12.2 & 12.2 \\
\hline WBC count, $\left(\times 10^{3} / \mu \mathrm{L}\right)$ & $4.5-11.0$ & 9.3 & 11.4 & & 12.73 & 10.62 \\
\hline WBC Diff., neutrophils, (\%) & $40-75$ & 64.7 & 88.8 & & 70.0 & 66.9 \\
\hline BUN, (mg/dL) & $7-23$ & 19.0 & 15.2 & 12.9 & 17.0 & 22.8 \\
\hline Creatinine, (mg/dL) & $0.7-1.4$ & 1.5 & 1.34 & 1.11 & 1.07 & 1.16 \\
\hline Alkaline phosphatase, (U/L) & $30-120$ & 162 & 166 & & & 116 \\
\hline Alanine aminotransferase, (U/L) & $3-45$ & 357 & 270 & 273 & 138 & 47 \\
\hline Aspartate aminotransferase, (U/L) & $3-45$ & 278 & 221 & 147 & 49 & 27 \\
\hline Total cholesterol, (mg/dL) & $130-240$ & 222 & & & & \\
\hline LDL cholesterol, (mg/dL) & $50-160$ & 136 & & & & \\
\hline HDL cholesterol, (mg/dL) & $40-85$ & 74 & & & & \\
\hline Triglycerides, (mg/dL) & $35-200$ & 127 & & & & \\
\hline Creatine kinase, (IU/L) & 43-198 & 9300 & 9936 & 1530 & 632 & 235 \\
\hline Lactate dehydrogenase, (IU/L) & $238-422$ & 1876 & 1818 & 1508 & 1333 & 457 \\
\hline Myoglobulin, (ng/mL) & $28-72$ & 636 & 428 & & 61 & 47 \\
\hline CK-MB, (ng/mL) & $0-4.87$ & 52.07 & 42.60 & & 11.24 & 5.94 \\
\hline Troponin I, (ng/mL) & $0-0.014$ & 0.057 & & & & \\
\hline $\mathrm{TSH},(\mu \mathrm{IU} / \mathrm{mL})$ & $0.17-4.05$ & $>100$ & & 53.65 & & 48.17 \\
\hline fT4, ( $\mu \mid \mathrm{U} / \mathrm{mL})$ & $0.89-1.79$ & 0.32 & & 0.65 & & 1.63 \\
\hline T3, (ng/dL) & $78-182$ & 55.6 & & 71.6 & & 86.2 \\
\hline
\end{tabular}

Abbreviations: $B U N$ blood urea nitrogen, $C K-M B$ creatine kinase muscle-brain fraction, TSH thyroid stimulating hormone, $f T 4$ free thyroxine, $T 3$ triiodothyronine, WBC white blood cell, $L D L$ low density lipoprotein, $H D L$ high density lipoprotein 

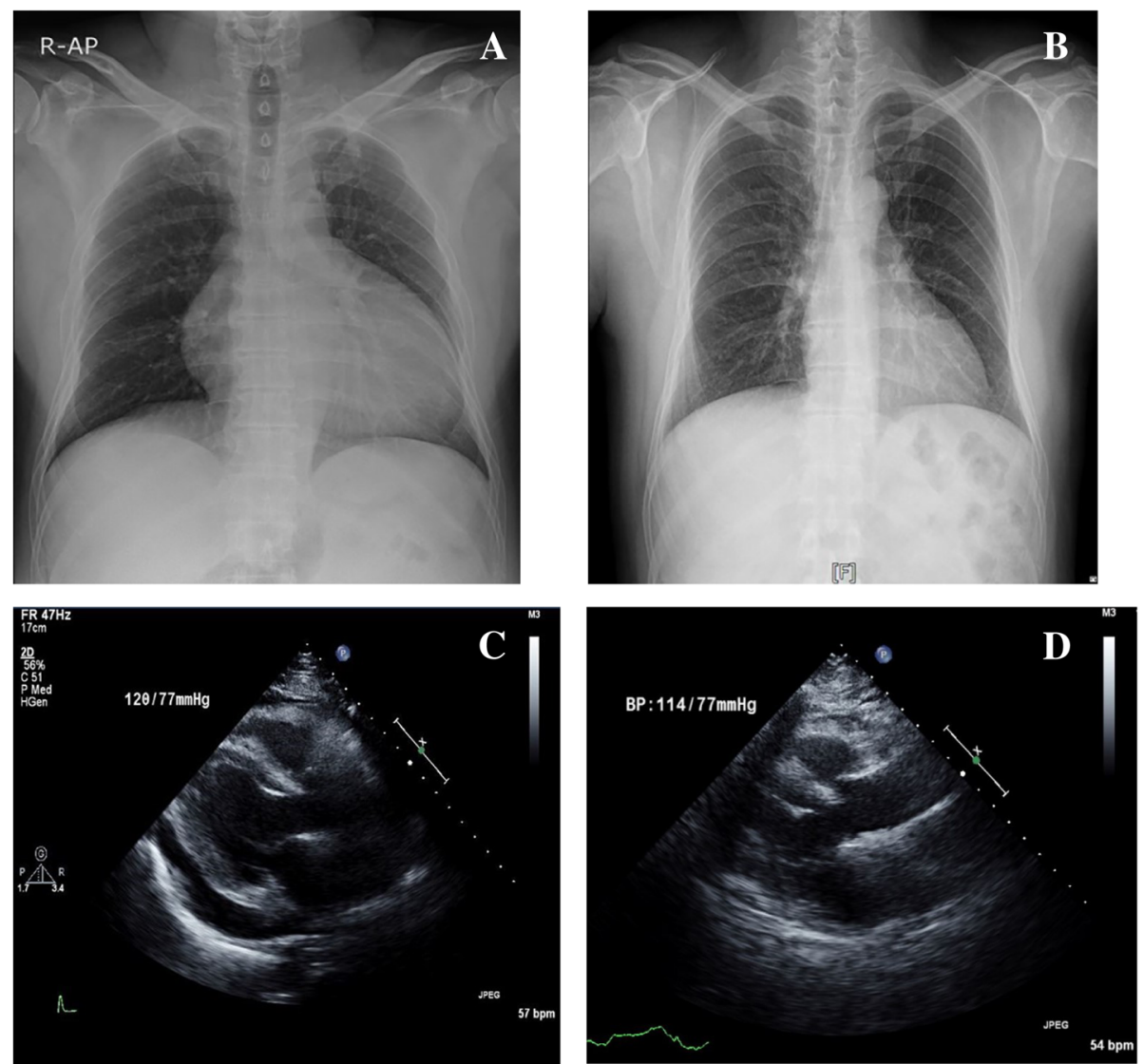

Fig. 1 Image findings of the patient. Chest radiography shows cardiomegaly without pleural effusion at initial admission (a) and decreased cardiomegaly after discharge (b). Transthoracic echocardiography shows moderate pericardial effusion at initial admission (c) and completely recovered pericardial effusion at one-year later (d)

$\mathrm{mm}$ ) with preserved left ventricular systolic function (55$60 \%$; Fig. 1c). On further investigation, pure tone audiometry revealed that the patient had profound unilateral sensorineural hearing loss (Fig. 2a), and thyroid sonography showed diffusely enlarged gland with a heterogeneous echotexture and decreased vascularity (Fig. 3); these findings are consistent with Hashimoto thyroiditis together with elevated thyroid peroxidase antibodies (> 2000 [0$5.61] \mathrm{IU} / \mathrm{mL}$ ) and antithyroglobulin antibodies $(9143.72$ [0-4.11] IU/mL).

Upon admission, we started aggressive intravenous fluid resuscitation to treat rhabdomyolysis with acute kidney injury and levothyroxine replacement (oral, $150 \mathrm{mcg} /$ day) to treat hypothyroidism. We also started systemic corticosteroids and intratympanic steroid injection to treat sensorineural hearing loss. The patient did not require pericardiocentesis because there was no ventricular dysfunction, and his vital signs were comparatively stable. Over the next several days, the patient's clinical symptoms, such as shortness of breath, general weakness, and lower limb discomfort, improved substantially. On consecutive laboratory tests, creatine kinase as well as lactate dehydrogenase began to decrease on hospital day (HD) 3 and continued to decline to $1530 \mathrm{IU} / \mathrm{L}$ and $1508 \mathrm{IU} / \mathrm{L}$ on HD 7, respectively. Creatinine also started to decrease by $1.11 \mathrm{mg} / \mathrm{dL}$ on HD 7 accompanied by creatine kinase decline. Further thyroid function testing showed that his TSH was $53.65 \mu \mathrm{IU} / \mathrm{mL}$ and fT4 was $0.63 \mu \mathrm{IU} / \mathrm{mL}$ on $\mathrm{HD}$ 7. The patient was discharged home on HD 10 with instructions to continue levothyroxine $(150 \mathrm{mcg} /$ day, oral).

The patient was examined in the outpatient clinic 2 weeks after discharge. We observed recovered creatinine and creatinine kinase (Table 1) as well as improved cardiomegaly (Fig. 1b). Except for hearing loss, his clinical symptoms continued to improve, and he was compliant with levothyroxine treatment. His thyroid function was normalized at 5 months (TSH $0.10 \mu \mathrm{IU} / \mathrm{mL}$, free T4 1.60 $\mu \mathrm{IU} / \mathrm{mL}$ ) and remained euthyroid status until one year after discharge (TSH $0.54 \mu \mathrm{IU} / \mathrm{mL}$, free T4 $1.52 \mu \mathrm{IU} /$ $\mathrm{mL}$ ). No pericardial effusion appeared on transthoracic echocardiography (Fig. 1d). Regarding hearing loss, there was slight improvement in follow-up pure tone audiometry after 1 year; nevertheless, profound unilateral hearing loss remained in this patient (Fig. 2b). 
A

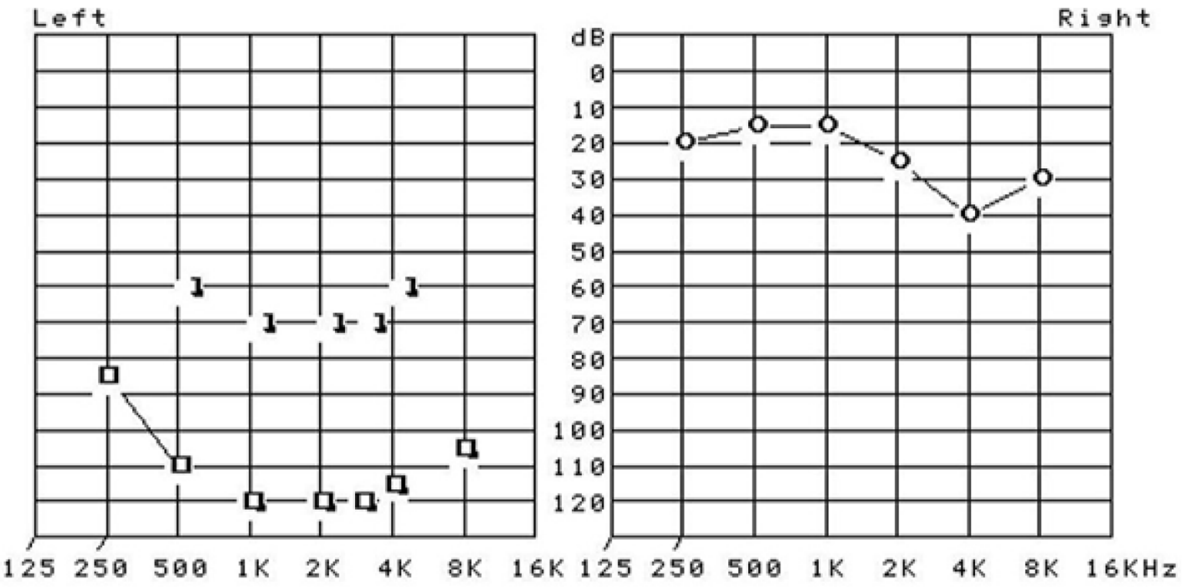

B

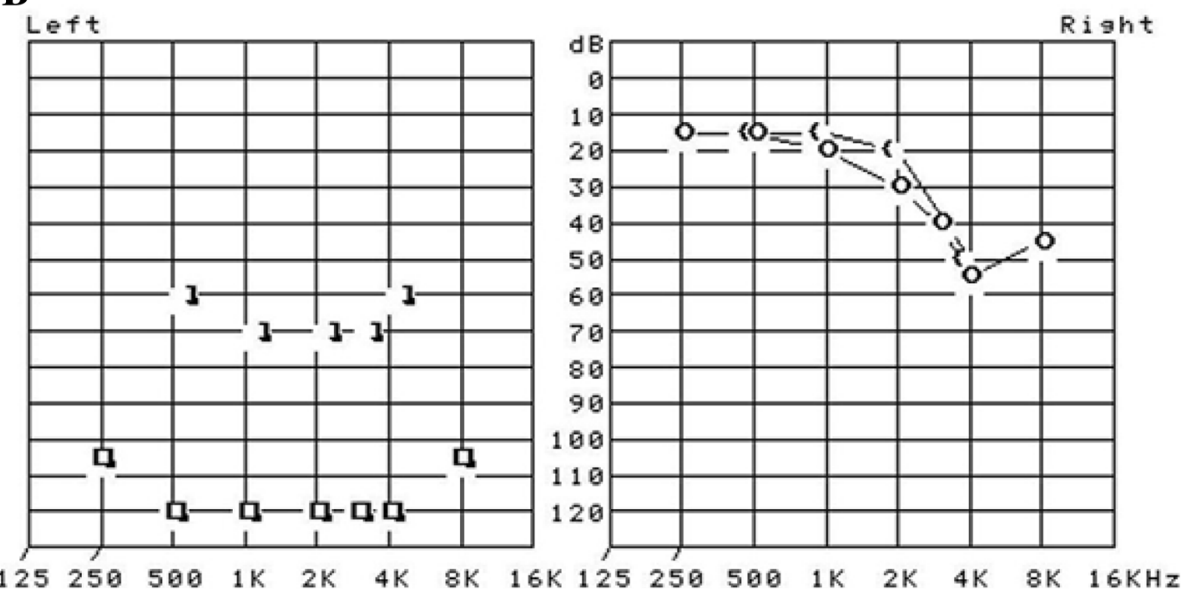

Fig. 2 Pure tone audiometry displayed the presence of unilateral (left side) profound sensorineural hearing loss at initial diagnosis (a) and remained hearing loss at one-year after discharge $(\mathbf{b})$

\section{Discussion and conclusions}

Hypothyroidism is an endocrine disorder commonly encountered in real medical practice. Although clinical symptoms of hypothyroidism are generally diverse and nonspecific, it is seemingly straightforward to diagnose by means of simple and accurate laboratory tests. However, despite its simple and common diagnosis, it is difficult to speculate subsequent complications of hypothyroidism. Within this context, this report has shown simultaneous rare complications accompanying rhabdomyolysis, pericardial effusion, and sudden sensorineural hearing loss in the patient with untreated hypothyroidism. This case reminds physicians of the importance of timely diagnosis and proper treatment in hypothyroidism patients. Moreover, we should keep an eye on the critical complications, albeit uncommon, like rhabdomyolysis, pericardial effusion, and sudden sensorineural hearing loss in untreated hypothyroidism patients.
There have been several reports of hypothyroidisminduced rhabdomyolysis $[8,9,11,12]$, hypothyroidisminduced pericardial effusion [13, 14], and sensorineural hearing loss related to autoimmune thyroid disease [15-17] in recent decades. Zare-khormizi et al. presented the case of a patient with massive pericardial effusion and rhabdomyolysis secondary to untreated severe hypothyroidism [18]. However, to our best knowledge, ours is the first case report of simultaneous occurrence of rhabdomyolysis with acute kidney injury, moderate pericardial effusion, and sudden sensorineural healing loss in a patient with hypothyroidism.

Rhabdomyolysis, characterized by rapid skeletal muscle breakdown and release of intracellular muscle constituents into circulation, should be differentially diagnosed from other conditions [19]. Traumatic causes such as crush injury, multiple trauma, and immobilization as well as nontraumatic causes including extreme exercise, 


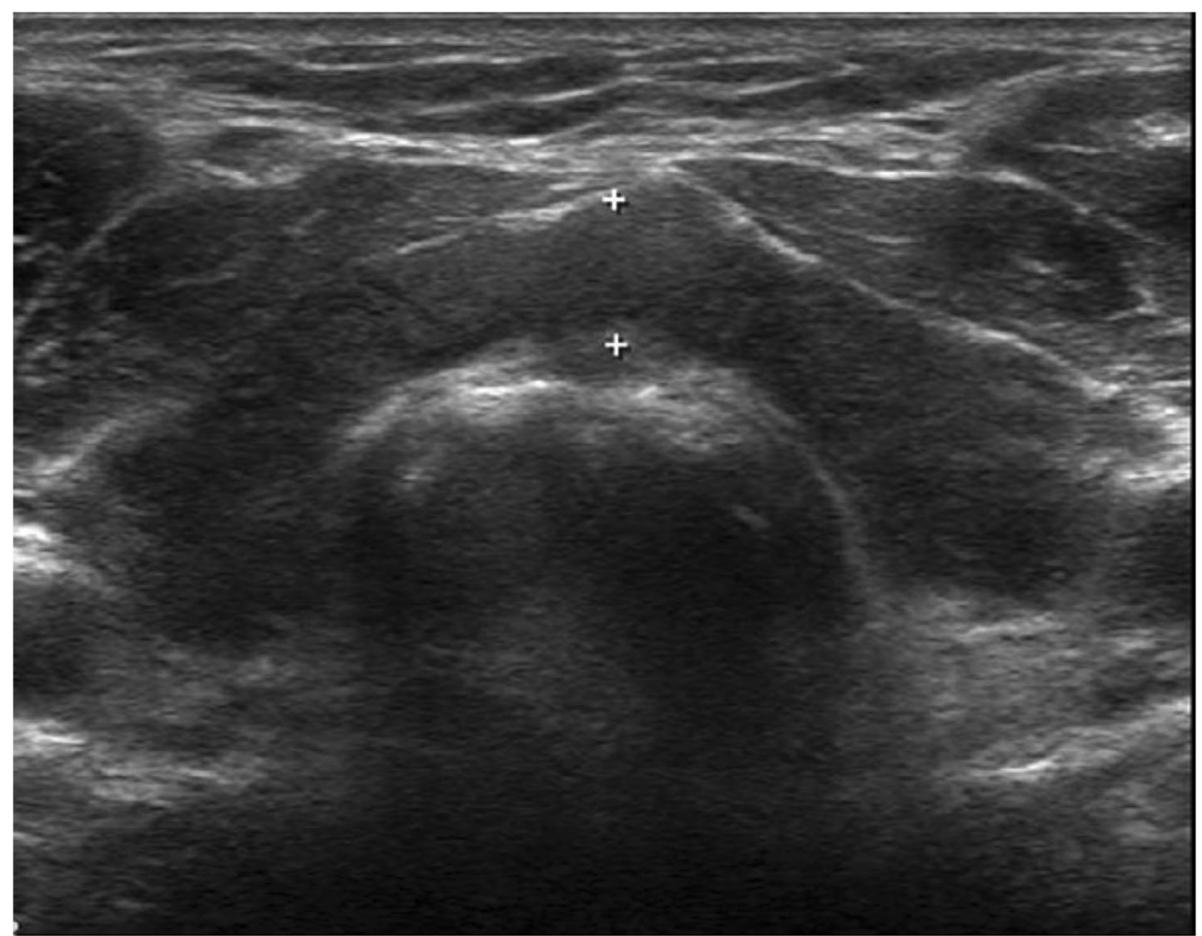

Fig. 3 Transverse view of thyroid sonography revealed marked heterogenous echotexture of both thyroid glands

seizure, infection, and alcohol and drug abuse are well-known etiologies of rhabdomyolysis. High-dose statin treatment for hypercholesterolemia has recently been reported to cause rhabdomyolysis [20]. In the present case, the patient had been taking rosuvastatin $5 \mathrm{mg}$ once daily for a year, which was not so potent dosage as to induce rhabdomyolysis; rosuvastatin is known as a more hydrophilic statin and is therefore less likely to enter the myocytes [21]. Moreover, no dosage changes were prescribed in this patient during treatment. He also had no history of trauma, other than drug abuse or alcohol intoxication. For these reasons, we deduced that the main cause of rhabdomyolysis was primary hypothyroidism. However, there is also a possibility that statin therapy and untreated hypothyroidism may synergistically enhance the risk of myopathy and rhabdomyolysis in patients as reported in the literature [22, 23]. The pathophysiology between rhabdomyolysis and hypothyroidism have not been clearly elucidated; however, thyroid hormone seems to be associated with glycogenolysis and mitochondrial oxidative metabolism in myocytes [24]. Furthermore, acute kidney injury in our case could be induced by rhabdomyolysis rather than hypothyroidism itself. Although hypothyroidism is known to affect renal impairment, increased creatinine was normalized in a short time after fluid resuscitation, consistent with creatine kinase decline, suggesting that decreased renal function was more likely associated with rhabdomyolysis than hypothyroidism.
Thyroid hormone is closely related to cardiac function, and pericardial effusion in patients with hypothyroidism is an infrequent manifestation. Decreased thyroid hormone is associated with protein extravasation and reduced lymphatic drainage, which leads to myxedema with fluid accumulation in the pericardial cavity $[25,26]$. Cardiac tamponade has also been reported as a manifestation of severe hypothyroidism [27]. Therefore, it is reasonable to assess thyroid function in patients presenting with pericardial effusion or cardiac tamponade. Fortunately, in our patient, there was no evidence of cardiac tamponade and pericardial effusion decreased after levothyroxine treatment, without the need for pericardiocentesis.

Sudden sensorineural hearing loss is defined as acute onset of hearing loss of at least $30 \mathrm{~dB}$ occurring over a 72-h period and is nearly involving unilateral [28]. Identifiable causes are found in only $7-45 \%$ of patients with sudden sensorineural hearing loss. The most common causes are infectious diseases such as HIV, mycoplasma infection, or syphilis followed by otologic trauma or vascular, hematologic, or metabolic disorders such as hypothyroidism and diabetes mellitus [29]. Thyroid dysfunction can be found in patients presenting with sudden sensorineural hearing loss, with one report of a $15 \%$ rate of hypothyroidism [30]. However, metabolic disorders including hypothyroidism usually involve bilateral hearing loss [31]. Additional brain computed tomography (CT) and brain CT angiography conducted to find out other causes 
related to unilateral hearing loss did not detect any significant findings, and further brain magnetic resonance imaging could not be performed due to the patient's refusal. Although we cannot completely exclude the possibility that the sensorineural hearing loss was not induced by hypothyroidism, it is more plausible to speculate that sudden sensorineural hearing loss was associated with untreated hypothyroidism in this patient who already have experienced hypothyroidism-related symptoms and complications like rhabdomyolysis and pericardial effusion. How to define the relationship between hypothyroidism and the auditory organ remains to be further investigated. Previous reports have suggested that thyroid autoantibodies, such as thyroglobulin antibody and thyroid peroxidase antibody, have a role in peripheral and central hearing organ dysfunction [17]. The prognosis of sudden sensorineural hearing loss is generally favorable; however, hearing loss in this case was not completely recovered even after glucocorticoid injection and levothyroxine treatment. Profound hearing loss at initial diagnosis across all frequencies is considered a risk factor for incomplete recovery [32].

In the current guidelines of the American Association of Clinical Endocrinologists and American Thyroid Association (AACE/ATA), thyroid function testing is recommended in patients with congestive heart failure, dementia, myopathy, and vitiligo to detect hypothyroidism [1]. Herein, we report for the first time a case of untreated hypothyroidism with concurrent rhabdomyolysis with acute kidney injury, pericardial effusion, and sudden sensorineural hearing loss. Our case report underlines the importance of appropriate diagnosis and treatment of hypothyroidism and suggests that it is reasonable to scrutinize thyroid function in patients with unexplained hearing loss and pericardial effusion as well as rhabdomyolysis.

\section{Abbreviations}

BUN: Blood urea nitrogen; CK-MB: Creatine kinase muscle-brain fraction; fT4: Free thyroxine; HD: Hospital day; HIV: Human immunodeficiency virus; T3: Triiodothyronin; TSH: Thyroid stimulating hormone

\section{Acknowledgments}

Not applicable.

\section{Funding}

None.

\section{Availability of data and materials}

Public accessibility to the raw data of this case report is unavailable, to protect patient privacy and respect confidentiality. The original laboratory and imaging results as well as outpatient clinical records are retained according to our institutional medical record system. Datasets are available from the corresponding author on reasonable request.

\section{Authors' contributions}

CGS and KJK2 were responsible for patient management and participated in writing the manuscript. EP contributed to relevant discussions regarding sensorineural hearing loss and edited the manuscript. KJK1, NHK, JHK, HYK, and SGK participated in discussions and revised the manuscript. KJK2 was responsible for data integrity and accuracy as well as data accessibility. Al authors have read and approved the final manuscript.
Ethics approval and consent to participate

Ethics approval was waivered as this case report was not considered a clinical study according to the Ethics Committee of Korea University Anam Hospital, Korea University College of Medicine.

\section{Consent for publication}

Written informed consent was obtained from the patient for publication of this case report.

\section{Competing interests}

The authors declare that they have no competing interests.

\section{Publisher's Note}

Springer Nature remains neutral with regard to jurisdictional claims in published maps and institutional affiliations.

\section{Author details}

${ }^{1}$ Division of Endocrinology and Metabolism, Department of Interna Medicine, Korea University Anam Hospital, Korea University College of Medicine, 73 Inchon-ro, Seongbuk-gu, Seoul 02841, Republic of Korea. ${ }^{2}$ Department of Otolaryngology-Head and Neck Surgery, Korea University Anam Hospital, Korea University College of Medicine, Seoul, South Korea.

Received: 31 January 2019 Accepted: 9 May 2019

Published online: 22 May 2019

\section{References}

1. Garber JR, Cobin RH, Gharib H, Hennessey JV, Klein I, Mechanick Jl, et al. Clinical practice guidelines for hypothyroidism in adults: cosponsored by the American Association of Clinical Endocrinologists and the American Thyroid Association. Thyroid. 2012;22:1200-35.

2. Zimmermann MB, Boelaert K. lodine deficiency and thyroid disorders. Lancet Diabetes Endocrinol. 2015;3:286-95.

3. Taylor PN, Albrecht D, Scholz A, Gutierrez-Buey G, Lazarus JH, Dayan CM, et al. Global epidemiology of hyperthyroidism and hypothyroidism. Nat Rev Endocrinol. 2018;14:301-16.

4. Sawin CT, Castelli WP, Hershman JM, McNamara P, Bacharach P. The aging thyroid: thyroid deficiency in the Framingham study. Arch Intern Med. 1985; 145:1386-8.

5. Vanderpump M, Tunbridge W, French J, Appleton D, Bates D, Clark F, et al. The incidence of thyroid disorders in the community: a twenty-year followup of the Whickham survey. Clin Endocrinol. 1995:43:55-68.

6. Vanderpump MP, Tunbridge WMG. Epidemiology and prevention of clinical and subclinical hypothyroidism. Thyroid. 2002;12:839-47.

7. Chaker L, Bianco AC, Jonklaas J, Peeters RP. Hypothyroidism. Lancet. 2017; 390:1550-62.

8. Katipoglu B, Ates I, Acehan F, Meteris A, Y.Imaz N. Rhabdomyolysis case based on hypothyroidism. Endocrinol Diabetes Metab Case Rep. 2016. https://doi.org/10.1530/EDM-16-0083.

9. Cai $Y$, Tang $L$. Rare acute kidney injury secondary to hypothyroidisminduced rhabdomyolysis. Yonsei Med J. 2013;54:172-6.

10. Ates I, Kaplan M, Yilmaz N. Newly diagnosed primary hypothyroidism applicant with massive pericardial effusion and acute renal failure. Endocr Regul. 2016;50:24-6.

11. Salehi N, Agoston E, Munir I, Thompson GJ. Rhabdomyolysis in a patient with severe hypothyroidism. Am J Case Rep. 2017;18:912-8.

12. Naz A, Issa M. Rhabdomyolysis and acute renal impairment in a patient with hypothyroidism: a case report. Case Rep Med. 2014. https://doi.org/10.1155/ 2014/139170.

13. Perttunen $H$, Maack C. Pericardial effusion associated with hypothyroidism in an adult female with Down syndrome. Am J Med Genet A. 2015;167: 1674-5.

14. Leonardi A, Penta L, Cofini M, Lanciotti L, Principi N, Esposito S. Pericardial effusion as a presenting symptom of Hashimoto thyroiditis: a case report. Int J Environ Res Public Health. 2017. https://doi.org/10.3390/ ijerph14121576.

15. Karakus CF, Altuntaş EE, Kılıçı F, Durmuş K, Hasbek Z. Is sensorineural hearing loss related with thyroid metabolism disorders. Indian J Otol. 2015; 21:138-43. 
16. Arduc A, Isık S, Allusoglu S, Iriz A, Dogan BA, Gocer C, et al. Evaluation of hearing functions in patients with euthyroid Hashimoto's thyroiditis. Endocrine. 2015;50:708-14.

17. Chiarella G, Russo D, Monzani F, Petrolo C, Fattori B, Pasqualetti G, et al. Hashimoto thyroiditis and vestibular dysfunction. Endoc Pract. 2017;23:863-8.

18. Zare-Khormizi MR, Rahmanian M, Pourrajab F, Akbarnia S. Massive pericardial effusion and rhabdomyolysis secondary to untreated severe hypothyroidism: the first report. Acta Clin Belg. 2014;69:375-8.

19. Zimmerman JL, Shen MC. Rhabdomyolysis. Chest. 2013;144:1058-65.

20. Sathasivam S, Lecky B. Statin induced myopathy. BMJ. 2008;337:a2286.

21. Sathasivam S. Statin induced myotoxicity. Eur J Intern Med. 2012;23:317-24.

22. Yeter E, Keles T, Durmaz T, Bozkurt E. Rhabdomyolysis due to the additive effect of statin therapy and hypothyroidism: a case report. J Med Case Rep. 2007;1:130.

23. Tokinaga K, Oeda T, Suzuki Y, Matsushima Y. HMG-CoA reductase inhibitors (statins) might cause high elevations of creatine phosphokinase (CK) in patients with unnoticed hypothyroidism. Endocr J. 2006:53:401-5.

24. Kisakol G, Tung R, Kaya A. Rhabdomyolysis in a patient with hypothyroidism. Endocr J. 2003;50:221-3.

25. Klein I, Danzi S. Thyroid disease and the heart. Curr Probl Cardiol. 2016;41: 65-92.

26. Grais IM, Sowers JR. Thyroid and the heart. Am J Med. 2014;127:691-8.

27. Patil VC, Patil HV, Agrawal V, Patil S. Cardiac tamponade in a patient with primary hypothyroidism. Indian J Endocrinol Metab. 2011;15(Suppl 2):144-6.

28. Stachler RJ, Chandrasekhar SS, Archer SM, Rosenfeld RM, Schwartz SR, Barrs DM, et al. Clinical practice guideline: sudden hearing loss. Otolaryngol Head Neck Surg. 2012;146(Suppl 3):1-35.

29. Kuhn M, Heman-Ackah SE, Shaikh JA, Roehm PC. Sudden sensorineural hearing loss: a review of diagnosis, treatment, and prognosis. Trends Amplif. 2011;15:91-105.

30. Narozny W, Kuczkowski J, Mikaszewski B. Thyroid dysfunction underestimated but important prognostic factor in sudden sensorineural hearing loss. Otolaryngol Head Neck Surg. 2006;135:995-6.

31. Plontke SK. Diagnostics and therapy of sudden hearing loss. GMS Curr Top Otorhinolaryngol Head Neck Surg. 2017;16 Doc05. Doi:10.3205/cto000144.

32. Wen YH, Chen PR, Wu HP. Prognostic factors of profound idiopathic sudden sensorineural hearing loss. Eur Arch Otorhinolaryngol. 2014;271:1423-9.

Ready to submit your research? Choose BMC and benefit from:

- fast, convenient online submission

- thorough peer review by experienced researchers in your field

- rapid publication on acceptance

- support for research data, including large and complex data types

- gold Open Access which fosters wider collaboration and increased citations

- maximum visibility for your research: over $100 \mathrm{M}$ website views per year

At $\mathrm{BMC}$, research is always in progress.

Learn more biomedcentral.com/submissions 